UCRL-JC-119536

CONF $-950476-16$

\title{
High Convergence, Indirect Drive Inertial Confinement Fusion Experiments at Nova
}

\author{
RECENED \\ FFP O 61998 \\ R. A. Lerche, M. D. Cable, S. P. Hatchett, J. A. Carid, \\ OSTI \\ J. D. Kilkenny, H. N. Kornblum, S. M. Lane, C. Laumann, \\ T. J. Murphy, J. Murray, M. B. Nelson, D. W. Phillion, \\ H. Powell, and D. Ress
}

This paper was prepared for submittal to the 12th International Conference on Laser Interaction and Related Plasma Phenomena

Osaka, Japan

April 24-28, 1995

June 2, 1995

This is a preprint of a paperintended for publication in a journal or proceedings. Since changes may be made before publication, this preprint is made available with the understanding that it will not be cited or reproduced without the permission of the author. 


\section{DISCLAIMER}

This document was prepared as an account of work sponsored by an agency of the United States Government. Neither the United States Government nor the University of Califomia nor any of their employees, makes any warranty, express or implied, or assumes any legal liability or responsibility for the accuracy, completeness, or usefulness of any information, apparatus, product, or process disclosed, or represents that its use would not infringe privately owned rights. Reference herein to any specific commercial product, process, or service by trade name, trademark, manufacturer, or otherwise, does not necessarily constitute or imply its endorsement, recommendation, or favoring by the United States Government or the University of California. The views and opinions of authors expressed herein do not necessarily state or reflect those of the United States Government or the University of California, and shall not be used for advertising or product endorsement purposes. 


\title{
High Convergence, Indirect Drive Inertial Confinement Fusion Experiments at Nova
}

\author{
R. A. Lerche, M. D. Cable, S. P. Hatchett, J. A. Caird, \\ J. D. Kilkenny, H. N. Kornblum, S. M. Lane, C. Laumann, \\ T. J. Murphy, J. Murray, M. B. Nelson, D. W. Phillion, H. Powell, \\ and D. Ress
}

Lawrence Livermore National Laboratory, P.O. Box 5508, L-473, Livermore, CA 94550

\begin{abstract}
High convergence, indirect drive implosion experiments have been done at the Nova Laser Facility. The targets were deuterium and deuterium/tritium filled, glass microballoons driven symmetrically by $\mathrm{x}$ rays produced in a surrounding uranium hohlraum. Implosions achieved convergence ratios of $24: 1$ with fuel densities of $19 \mathrm{~g} / \mathrm{cm}^{3}$; this is equivalent to the range required for the hot spot of ignition scale capsules. The implosions used a shaped drive and were well characterized by a variety of laser and target measurements. The primary measurement was the fuel density using the secondary neutron technique (neutrons from the reaction ${ }^{2} \mathrm{H}\left({ }^{3} \mathrm{H}, n\right) 4 \mathrm{He}$ in initially pure deuterium fuel). Laser measurements include power, energy and pointing. Simultaneous measurement of neutron yield, fusion reaction rate, and $\mathrm{x}$-ray images provide additional information about the implosion process. Computer models are in good agreement with measured results.
\end{abstract}

\section{INTRODUCTION}

Experiments recently conducted at the Nova Laser Facility addressed the overall quality of inertial-confinement fusion (ICF) implosions. The experiments were designed to answer two questions: how well do the implosions work and how well can we model them? Many researchers believe high gain ICF will be achieved by hot spot ignition in which a relatively small mass of gaseous fuel at the center of a target heated to 5-10 keV will ignite a higher density, lower temperature gas surrounding the core [1,2]. Because existing lasers are too low in energy to achieve thermonuclear gain, a set of hydrodynamically equivalent implosions are used to demonstrate that important, scalable parameters of ignition capsules are scientifically and technologically achievable.

The implosion experiments described in this talk used gas-filled glass capsules that were symmetrically driven by $\mathrm{x}$ rays produced in a surrounding hohlraum or cavity [3]. These implosions simultaneously achieved high convergence ratios (initial capsule radius $R_{0}$ to final fuel radius $R_{\mathrm{f}}$ ) and implosion configurations of high density glass with hot gas fill that are equivalent to those required for ignition 

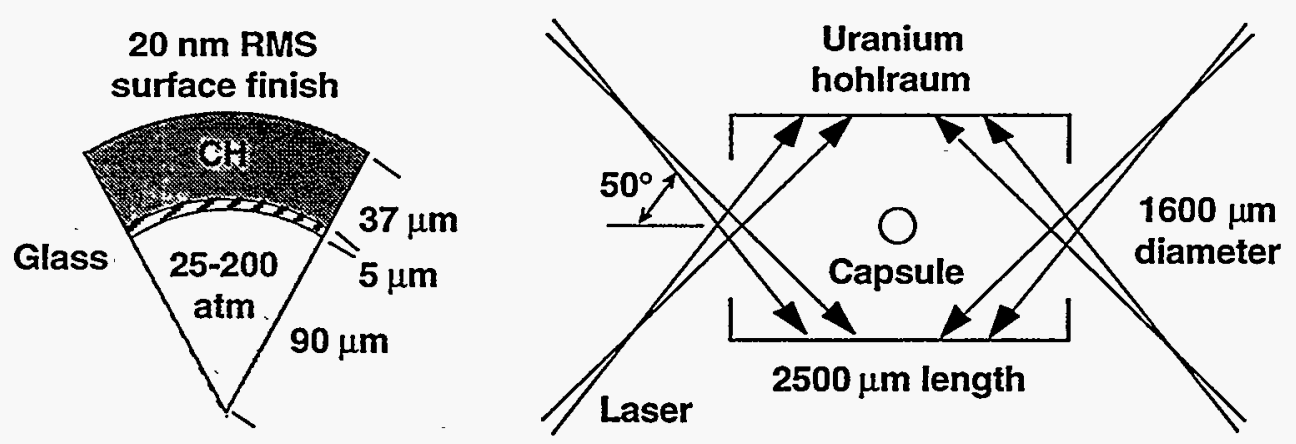

Figure 1. Geometry of glass microballoon and indirect drive hohlraum.

scale targets. The implosions, including nonideal effects, were modeled with detailed computer codes such as LASNEX (a radiation transport and hydrodynamics code). All observable quantities were in good agreement with simulations, demonstrating a good understanding of the energy transport and implosion hydrodynamics.

\section{IMPLOSION EXPERIMENTS}

The indirectly driven targets were gas-filled glass microballoons mounted inside uranium hohlraums (see Fig. 1). A relatively small $\left(R_{0} \doteq 90 \mu \mathrm{m}\right)$ capsule was selected to allow secondary neutrons to be used for fuel areal density measurements without saturation of the neutron spectrometer. Deuterium and equimolar deuterium/tritium fill pressure which ranged between 25 and 200 atm was used to vary capsule convergence while maintaining constant drive. The capsules were driven by $x$ rays produced when ten Nova laser beams with a total of $21 \mathrm{~kJ}$ of 0.35 $\mu \mathrm{m}$ light were incident on the interior wall of the hohlraum at an intensity of $2 \times$ $1015 \mathrm{~W} / \mathrm{cm}^{2}$. Laser beams were uniformly spaced around the circumference of two rings on the inner surface of the hohlraum.

Capsule implosion is driven by the ablation of the outer surface material of the capsule by $\mathrm{x}$ rays. The measured laser power and $\mathrm{x}$-ray drive temperature are shown in Fig. 2. Hohlraum temperature was measured using a time resolved, multichannel, $K$ - and $L$-edge filtered x-ray spectrometer [4]. Measurements were made looking at both the directly illuminated laser spots and the indirectly illuminated wall. Observed spectra were nearly Planckian. Laser pulse shape was selected to produce an $\mathrm{x}$-ray drive that optimized the pressure-density trajectory of the capsule without producing excessive hydrodynamic instability. Use of a uranium hohlraum and glass shell minimized x-ray preheating of the capsule.

$\mathrm{X}$-ray drive symmetry limits the convergence of these capsules. Drive uniformity for these cylindrically symmetric targets is usually expressed as in terms 

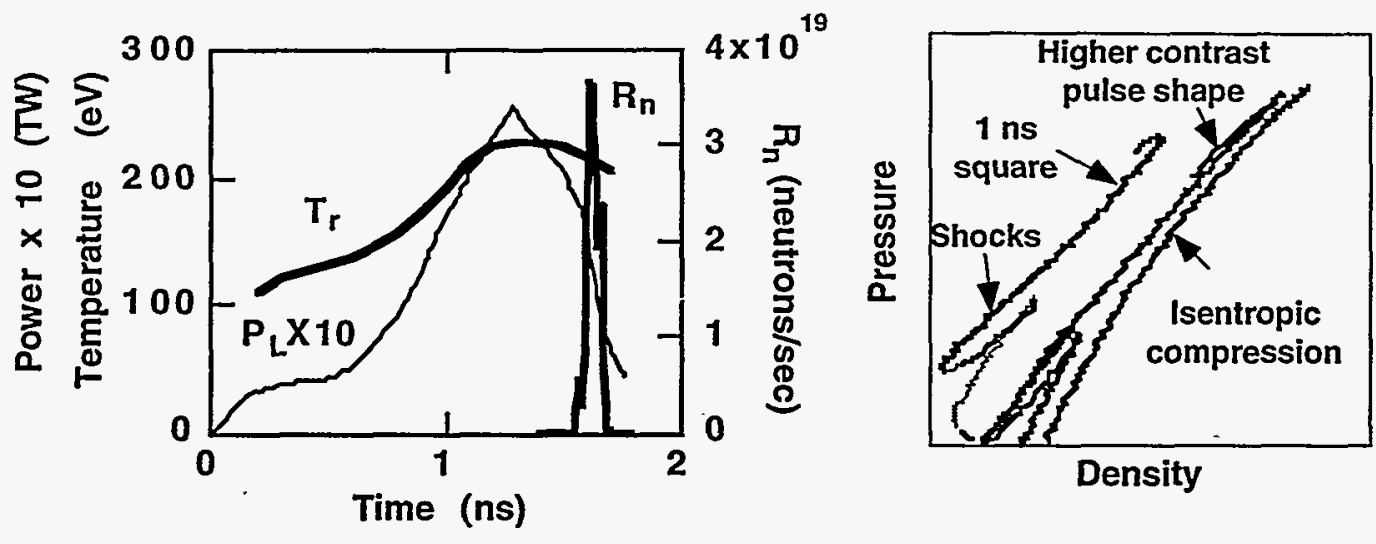

Figure 2. Observed laser power $\left(P_{L}\right)$, hohlraum temperature $\left(T_{r}\right)$, and neutron reaction rate $\left(R_{n}\right)$ for $100 \mathrm{~atm} D T$ filled capsule. Graph at right shows how high contrast pulse improves presure-density trajectory. More efficient compression is hydrodynamically less stable. These experiments have moderate growth factors of about 80 .

of Legendre polynomials. Symmetry eliminates the odd mode components while higher order even modes are relatively small because each point on the capsule surface views a large region of the hohlraum wall. Capsule dimensions and the laser irradiation point on the hohlraum wall are used to minimize the effect of the first two even moments $\left(P_{2}\right.$ and $\left.P_{4}\right)$. Symmetry changes during the laser pulse because both the wall albedo and the effective position of laser energy deposition moves. By design, simulations of this target show a $P_{2}$ asymmetry that changes sign during the pulse, averages to a low value, and is at most $8 \%$. Details of hohlraum design are reported by Suter et al. [5].

A second source of time-dependent drive asymmetry is imprecise power balance and pointing of the laser beams. During the period of these experiments, the "Precision Nova" project produced substantial improvements in beam-to-beam power balance, beam pointing, and beam synchronization. Power balance in the peak of the pulse was improved to $4 \%$ (RMS) and $8 \%$ in the foot; previously it had been 10 and $20 \%$ respectively. Beam pointing accuracy was improved from $\pm 100 \mu \mathrm{m}$ to $\pm 30 \mu \mathrm{m}$, and beam synchronization was improved from $25 \mathrm{ps}$ to $7 \mathrm{ps}$ (RMS).

Capsule convergence $\eta$ and final fuel density $\rho$ can be determined from the areal density of the compressed fuel, " $\rho R "=\int_{\text {fuel }} \rho R(r) d r$. If the fuel density is assumed to be uniform, then convergence is given by $\eta=R_{0} / R_{\mathrm{f}}=\left(\rho R / \rho_{0} R_{0}\right)^{1 / 2}$ and final density by $\rho=\rho R \eta / R_{0}$. Areal density was determined using the "secondary neutron" technique in which $\rho R$ is determined from the ratio of fusion neutrons produced by the secondary reaction $\mathrm{D}(T, n)^{4} \mathrm{He}$ to the number of neutrons produced 
by the $\mathrm{D}(\mathrm{D}, n)^{3} \mathrm{He}$ reaction in initially pure deuterium fuel. $\mathrm{A}$ "secondary neutron" is produced when a $1.01 \mathrm{MeV}$ triton produced by the $\mathrm{D}(\mathrm{D}, p) \mathrm{T}$ reaction interacts with a deuterium atom. If the tritons do not slow down significantly before they escape from the fuel, then the number of tritons producing neutrons is proportional to the fuel $\rho R$. The shape of the secondary neutron energy spectrum depends on the amount of slowing of the tritons and ranges between 12 to $17 \mathrm{MeV}$. For fuel in this work, significant triton slowing occurs for fuel densities above a few $\mathrm{mg} / \mathrm{cm}^{2}$ and corrections must be made for cross section energy dependence.

The primary diagnostic for these experiments was a sensitive neutron spectrometer [6]. It measures both the secondary neutron energy spectra and secondary neutron yield. The spectrometer consists of an array of 960 neutron timeof-flight detectors each capable of detecting single neutrons with an energy resolution of $150 \mathrm{keV}$. To complete a $\rho R$ measurement, the primary neutron yield was measured by measuring the activation of an In sample placed near the target.

\section{EXPERIMENTAL RESULTS}

In the initial set of experiments, the calculated density was not achieved for low fill pressures (see Fig. 3). Instead of increasing, density decreased at lower fill pressure. After the Precision Nova project was completed and beam balance and pointing improved, the experiments were repeated. This time observed density values increased significantly and matched calculated values. Measured fuel areal densities, which were as high as $16 \mathrm{mg} / \mathrm{cm}^{2}$, allowed the convergence ratios and fuel densities presented in Fig. 4 to be calculated. The measured values

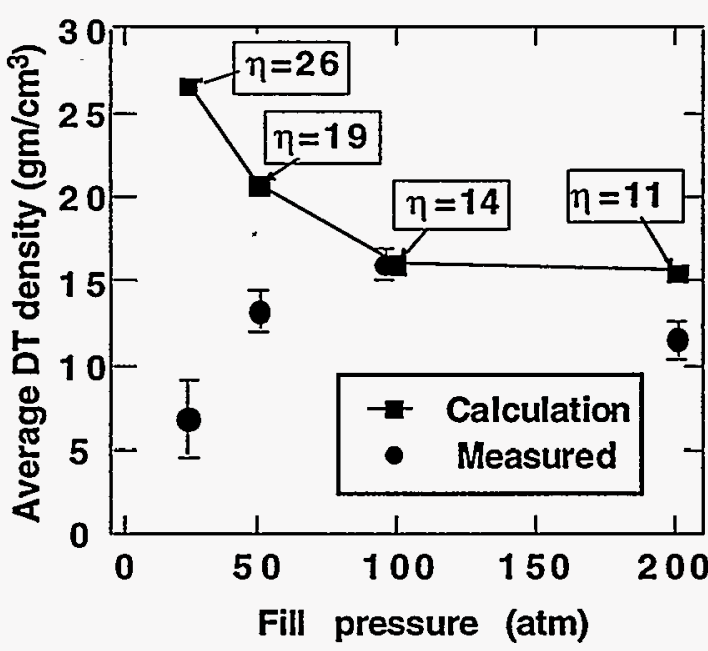

Figure 3. Density measurements made before the completion of "Precision Nova." the fuel region increases triton slowing and fuel mixing into the shell reduces are averages for several implosions ( 2 at 200 atm, 6 at $100 \mathrm{~atm}$, and 10 at $25 \mathrm{~atm}$ ); error bars are dominated by the statistics associated with the number of secondary neutrons recorded. For 25 atm capsules, convergence reached 24 with a final fuel density of $19 \mathrm{gm} / \mathrm{cm}^{3}$. Observed convergence and density values are consistent with simulations when the effects of fuelpusher mix are included at a level predicted with current models [7] for the capsule surface finish. Fuelpusher mix produces two important effects: high- $Z$ material moving into 

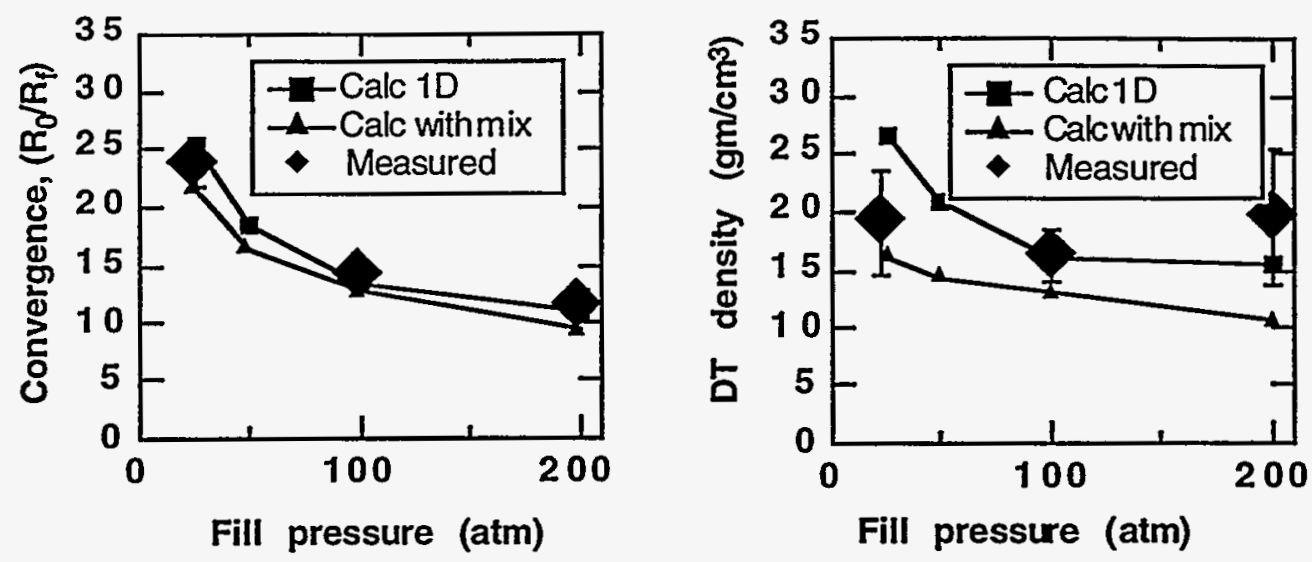

Figure 4. Observed and calulated fuel convergence and density. Measured were made after the completion of Precision Nova. Calculations are for clean 1D and with mix. Density is expressed as an equivalent deuterium-tritium fill even when the capsule is filled with deuterium.

convergence. The amount of triton slowing can be estimated from the shape of the secondary neutron spectrum. A spectrum obtained by summing the 25 atm capsule data (10 implosions) is shown in Fig. 5 along with a simulated spectrum that includes mix. The energy spectrum is in good agreement with simulation supporting the validity of the mix model.

A number of other experimental measurements were also made for these targets. Neutron yields ( $2.45 \mathrm{MeV}$ neutrons) for deuterium filled targets were $2 \times 10^{7}$ to $3 \times 10^{8}$, while equimolar deuterium/tritium capsules produced $3 \times 10^{8}$ to $3 \times 10^{9}$ neutrons (14 MeV) with the lower yields observed for the lower fill, higher convergence capsules. Pusher areal density was measured by activation of $\mathrm{Rb}$ dopants in the glass shell [8]. Observed glass shell areal densities were $73 \pm 16$ $\mathrm{mg} / \mathrm{cm}^{2}$ ( 2 shots at $100 \mathrm{~atm}$ ) and $60 \pm 19 \mathrm{mg} / \mathrm{cm} \quad 2$ (2 shots at $25 \mathrm{~atm}$ ), while simulations show 54 and $81 \mathrm{mg} / \mathrm{cm} \quad 2$, respectively. Fuel ion temperature was determined from the Doppler broadening of the primary neutron energy spectrum recorded with a time-of-flight detector that is separate and simpler than that used for the secondary neutrons[9]. Fuel temperatures for all fill pressures were $0.9 \pm 0.4$ $\mathrm{keV}$. Capsule burn duration and burn time relative to the laser pulse were determined with a fast scintillator-streak camera detector capable of 30 ps temporal resolution [10]. Burn for $100 \mathrm{~atm}$ capsules occurred at $1600 \pm 100 \mathrm{ps}$ and lasted for $50 \pm 15$ ps (see Fig. 2); simulations show 1603 ps and 33 ps, respectively. 


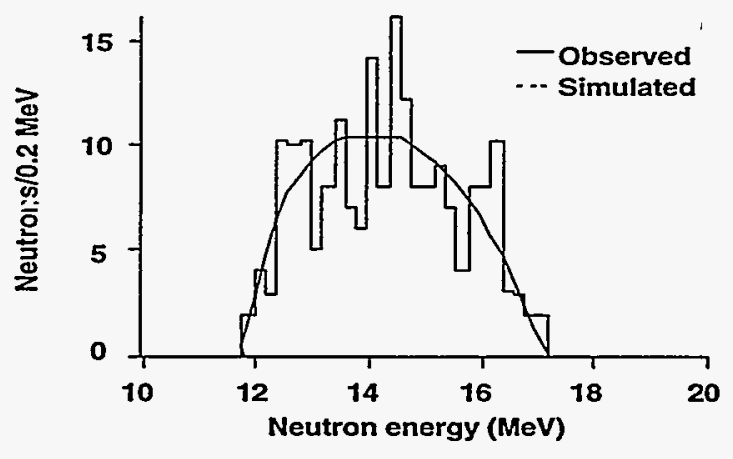

Figure 7. Secondary neutron energy spectrum. Observed data is the the sum of ten $25 \mathrm{~atm}$ capsules.

These experiments demonstrate the effect of improved "Precision Nova" beam quality and associated laser and target diagnostics on target performance. Through detailed comparisons between measured quantities and simulations, a deeper understanding was obtained for the sensitivity of the implosion process to laser and target parameters. In these experiments we demonstrated our ability to model and control implosion dynamics sufficient enough to achieve convergence levels comparable to those required for the hot spot of an ignition scale capsule.

This work was performed under the auspices of the U. S. Department of Energy by the Lawrence Livermore National Laboratory under Contract No. W7405-ENG-48.

\section{REFERENCES}

1. J. Nuckolls et al., Nature (London) 239, 139-142 (1972).

2. J. D. Lindl, R. L. McCrory, and E. M. Campbell, Phys. Today 45, No. 9, 32-40 (1992).

3. M. D. Cable et al, Phys. Rev. Lett. 73, 2316-2319, (1994).

4. H. N. Kornblum, R. L. Kauffman, and J. A. Smith, Rev. Sci. Instrum. 57, 2179 (1989).

5. L. Suter et al., Phys. Rev. Lett. 73, 2328 (1994).

6. M. B. Nelsom and M. D. Cable, Rev. Sci. Instrum. 63, 4874-4876 (1992).

7. S. Haan, Phys. Rev. A 39, 5812 (1989).

8. S. M. Lane and M. B. Nelson, Rev. Sci. Instrum. 61, 3298-3300 (1990)

9. T. J. Murphy and R. A. Lerche, Rev. Sci. Instrum. 63, 4883-4885 (1992).

10. R. A. Lerche, D. W. Phillion, and G. L. Tietbohl, Rev. Sci. Instrum. 66 933-935 (1995). 


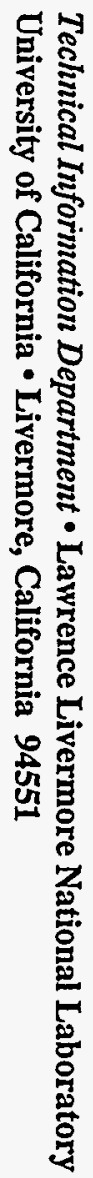

(3) 34 